\title{
In Niger, the Expected Futur Climate Will Provide Better Conditions than the Current One to Diospyros Mespiliformis Hochst. ex A.DC. Rich.
}

\author{
Ado ALI ${ }^{1}$, Laouali ABDOU ${ }^{2}$, Maman Maârouhi INOUSSA ${ }^{3}$, Josiane SEGHIERI ${ }^{4}$, Ali MAHAMANE ${ }^{3}$ \\ ${ }^{1}$ Université d'Agadez, Faculté des Sciences et Techniques; BP 199 Agadez; Niger \\ ${ }^{2}$ Université de Diffa, Faculté des Sciences Agronomiques, BP 78, Diffa, Niger \\ ${ }^{3}$ Université Abdou Moumouni de Niamey, Faculté des Sciences et Techniques, Département de Biologie \\ Laboratoire Garba Mounkaila, BP 10662 Niamey, Niger \\ ${ }^{4}$ UMR HydroSciences Montpellier, Université de Montpellier, CNRS, IRD, CC0057, 34090, Montpellier, France. \\ Correspondence: Ado ALI, Université d'Agadez, Faculté des Sciences et Techniques; BP 199 Agadez; Niger. Tel: \\ 227-9890-0215. E-mail: aaliadok@gmail.com
}

Received: May 26, 2020

doi:10.5539/enrr.v10n3p16
Accepted: September 2, 2020

Online Published: September 30, 2020

URL: https://doi.org/10.5539/enrr.v10n3p16

\begin{abstract}
The human use of plant resources and land to face increasing population needs in Africa to the regression or even the disappearance of some useful multi-purpose species such as Diospyros mespiliformis Hochst. Ex A. Rich. Increasing climatic variability is an additional threat for these species. The present study aims to identify the areas that are potentially favorable to $D$. mespiliformis conservation or regeneration in Niger and to analyze the impact of the current climate change. Thus to assess the D. mespiliformis distribution areas, the geographic coordinates of D. mespiliformis, the bioclimatic data, the soil and vegetation cover were collected and used to modeling based on the principle of maximum entropy (MaxEnt). The soil cover, annual cumulated precipitations and the average temperature are the most determining variables. This study also shows that the ecological niche of D. mespiliformis is located in the Central and Eastern bioclimates, within which almost 3\% of the surface is very favorable under the current climate conditions and may reach $3.94 \%$ under 2050 ones after. These results indicate that the climate change expected in Niger is expected to be more favorable to the studied species than the current climate conditions. This represents an opportunity for its domestication.
\end{abstract}

Keywords: A2 Scenario, climate change; Diospyros mespiliformis; Niger

\section{Introduction}

The management of a useful woody species requires a good knowledge of its range of life environmental conditions and the predicting effects of their change (Schmidt et al., 2008; Scheldeman and Van Zonneveld, 2010). Based on its presence, D. mespiliformis is among the species with broad geographical amplitude (Arbonier, 2004), with broad. This kind of distribution is generally done on a large-scale. The statistical modeling of the ecological niche of the species is an empirical tool of study of the environmental distribution of the species; the models obtained can be used to test through a statistical approach of the assumptions in ecology and biogeography (Sampoux \& Badeau, 2010). The most common approach is to establish a model in which the number of species is explained by mesologic variables (altitude, temperature, precipitation) (Dray, 1999). A good knowledge of spatial analysis allows the formulation and implementation of more targeted, and hence more effective, conservation strategies (Scheldeman and Van Zonneveld, 2010), in predicting effects of environmental change (Schmidt et al., 2008). That also makes it possible to have a prospective sight on the future of the flora with activities like the abusive cuts of wood and the climate changes. The automatic learning approaches, in particular MaxEnt, have been among the most successful for prediction (Elith et al., 2006). This approach has been adopted by several authors throughout the world to determine suitable habitats for species development (Araújo et al., 2005; Phillips et al., 2006; Doko et al., 2008; Kumar \& Stohlgren, 2009; Fandohan et al., 2013; Gbesso et al., 2013).The modeling of spaces where the environmental variables are favorable to the persistence or the distribution of the species is a quickly evolving field of science expanding with new methods (Guisan and Thuillier, 2005).This approach was adopted by several authors throughout the world to determine the habitats favorable to the development of species 
(Araújo et al., 2005; Phillips et al., 2006; Doko et al., 2008; Kumar \& Stohlgren, 2009; Fandohan et al., 2013; Gbesso et al., 2013, Laouali et al., 2016). From tropical Africa origin, D. mespiliformis is extremely widespread. Its distribution area extends from Senegal to Erythrea, Ethiopia and Kenya, and down to Namibia, to nothern South Africa and to Swaziland. It is almost missing in wetter forest of West and central Africa (Arbonier, 2004). It is of great agro-economic and ecological importance in the Sahel (Sop \& Oldeland, 2011; Thiombiano et al., 2013). However, it is endangered in overexploited places (Pounyala et al., 2014; Ali et al., 2016). Sustainable development and conservation policies of the species are requiered. To contribute to provide useful knowledges, the present study aims at:

i) determining the most favorable geographic areas for D. mespiliformis in Niger;

ii) forecasting their changes under expected climate conditions in 2050.

\section{Material and methods}

\subsection{Diospyros mespiliformis distribution area in Niger}

In Niger, D. mespiliformis was observed in the six following phytogeographical areas among those that were defined by Saadou (1990; Figure 1):

- $\quad$ western North-Sudanian area (A1): annual rainfall amount higher than $600 \mathrm{~mm}$, sparse dry forest on the laterite plateau, forest-gallery on the river banks, sparse-forest in the southern most clayey terraces and in the valleys, and savannas in the valleys and on the fixed dunes overhanging the valleys.

- $\quad$ central North-Sudanian area (A2): annual rainfall amount higher than $600 \mathrm{~mm}$, sparse dry forest on the plateaus, gallery-forests on the river banks s, savannas on the sandy terraces, the dunes, and the valleys.

- $\quad$ western South-Sahelian area (B1): annual rainfall amount between 400 and $600 \mathrm{~mm}$ Combretum on the laterite plateau, steppes on the sandy terraces, in the sandy valleys, and on the fixed dunes.

- $\quad$ central South-Sahelian area (B2): annual rainfall amount between 400 and $600 \mathrm{~mm}$, Combretum on the laterite plateau with savannas on the southernmost sandy terraces, and steppes on the dunes and in the sandy valleys.

- $\quad$ twestern North-Sahelian area (Cl): annual rainfall amount between 200 and $400 \mathrm{~mm}$, steppes in the clayey areas and shrubby steppes on the sandy substrates.

- $\quad$ eastern North-Sahelian area (C3): the same annual rainfall amount than the previous area, and covered by steppes.

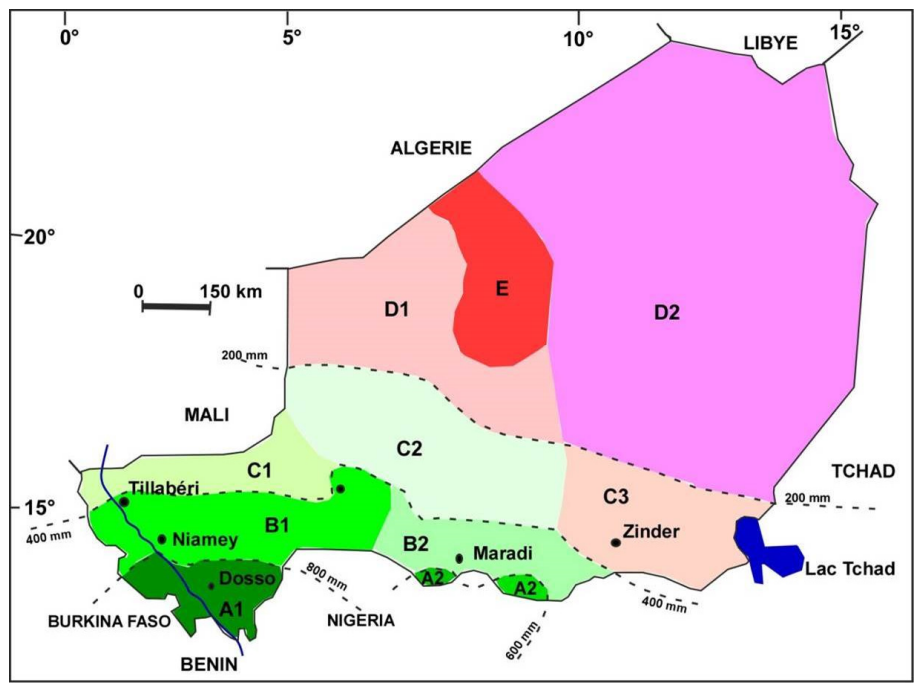

Figure 1. Phytogeographical subdivision of Niger (Saadou, 1990)

A1: Western North-Sudanian compartment; A2: central North-Sudanien compartment;

B1: Western South-Sahelian compartment; B2: Compartment central South-sahelian;

Cl: Western North-sahelian compartment; C2: Central North-sahelian compartment;

C3: Eastern North-sahelian compartment; D1: Central South-saharian compartment;

D2: Eastern South-Saharan compartment; E: Mountain South-Saharian compartment. 
The genus Diospyros is represented by more than 850 species in the world including 89 species in tropical Africa. It is a tree with evergreen or semi-deciduous, dioecious, small to medium-sized tree up to $25 \mathrm{~m}$ tall (El-kamali et al., 2011). It has a generally right and cylindrical trunk, deprived of branches on $18 \mathrm{~cm}$, up to $150 \mathrm{~cm}$ in diameter, sometimes grooved at the base or buttresses. Of tropical Africa origin except in wetland, D. mespiliformis is extremely widespread, from Senegal to Erythrea, Ethiopia and Kenya, and towards the south to Namibia, in the north from South Africa to Swaziland, but absent in almost wetter zones of forest of West and central Africa (Arbonier, 2004).

\subsection{Occurrences Data of D. mespiliformis}

The geographical coordinates (longitude and latitude) in decimal degree of D. mespiliformis were collected in the six phytogeographical compartments in sahelian and soudanian areas of Niger between 2014 and 2019 using a GPS. To these data, it is added those of Africa available on the site (http://www.gbif.org/occurrence/download) of GBIF. On the whole, 680 occurrence data of D. mespiliformis were collected (including 230 for ground work and 450 coming from GBIF). The (figure 2 presents the spatialization of the occurrence data used.

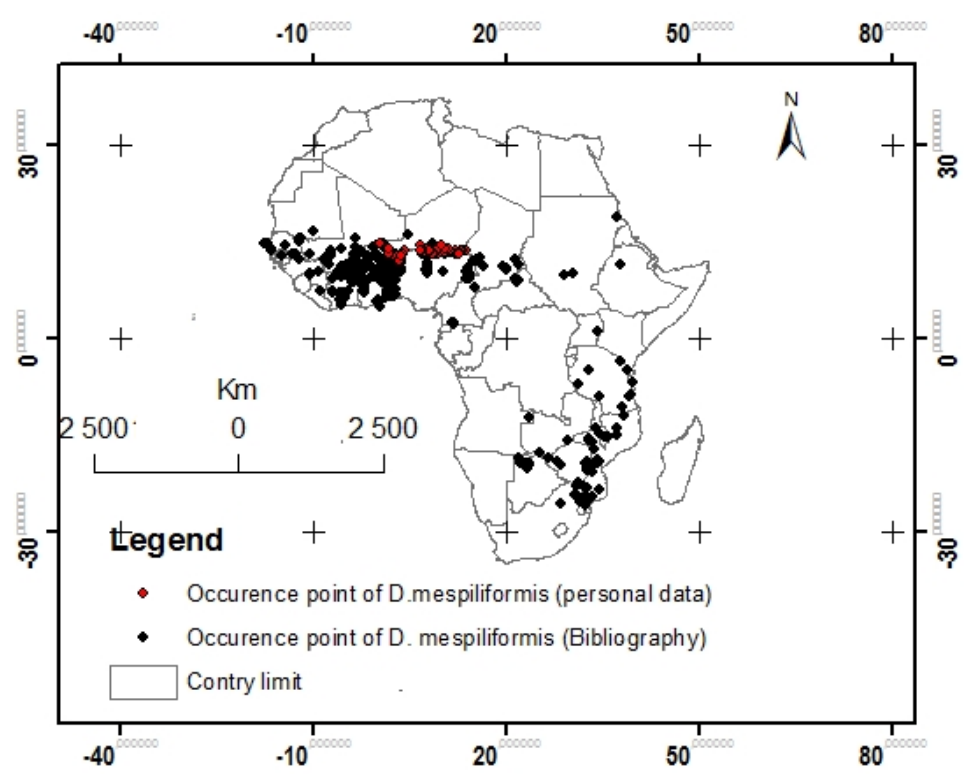

Figure 2. Occurence points of D. mespiliformis in Africa

\subsection{Environment Data}

To generate the ecological niche model of a species, it is necessary to have a data file of calibration combining data of occurrence of the species and environmental parameters values on some observation sites (Sampoux \& Badeau, 2009). Austin (2007) notes that the modeling of the ecological niche is in general more effective as the environmental parameters used are more direct (like temperature, solar radiation, and precipitations) and proximal. The association of indirect variables with the distribution observed leads to errors during projection (Pearson, 2010). Thus, two types of climatic data like direct parameters (precipitation and temperature monthly averages) of 50 years period (1950-2000) were collected and used for the modeling of the current niche of the species. These data with the format raster CLM, with 2.5 minutes a space resolution $(5 \mathrm{~km} \mathrm{X} 5 \mathrm{~km}=25 \mathrm{~km} 2$ for the pixel), were downloaded Worldclim (www.worldclim.org, consulted on 20/09/2019). The climatic data was associated with Soil cover downloaded from (http://webarchive.iiasa.ac.at/Research/LUC/External-World-soil-database ), altitude and vegetation cover downloaded from (https://research.cip.cgiar.org/).

For future climatic projections, three models of general circulation (Global Models Circulation: GCMs) among the most recommended (IPCC, 2007) were used: models CCCMA (Canadian Centers for Climate Modeling and Analysis), HadCM3 (Hadley Centre for Coupled Model version 3) and CSIRO (the Commonwealth Scientific and Industrial Research Organization). For all these models, the projections made for 2050 were used under the scenario of A2 emission. This scenario was used preferably because it predicts a more probable situation considered for Africa by 2050 (Williams et al., 2007). 


\subsection{Data Processing}

The species occurence data and the climate data were imported and treated with Diva-gis 7.5, Maxent 3.4.1. (Maximum Entropy Modeling) open-source software and ArcGIS. 10.4, a GIS sofware. MaxEnt (http://biodiversityinformatics.amnh.org/open_source/maxent) is a software that simulates species distributions from occurence-only species records. It has been used to estimate species distributions under climate change scenarios in an effort to determine suitable habitats for species development and evaluate management options (Fandohan et al., 2013; Gbesso et al., 2013, Laouali et al., 2016)

The first stage of the creation of the model of distribution is done by using the program Diva-gis to import altitude, precipitations and temperature monthly averages to create the climatic data in CLM (* clm) format then in the ASCII format (* asc) in order to obtain environmental rasters compatible with the MAXENT program. These rasters consists of 19 bioclimatic variables (http://worldclim.org/bioclim).

However, the climatic variables are very correlated (Zuur et al., 2009). It was thus necessary to carry out a selection. Maël et al., (2014) attested that a strong correlation between the variables could compromise the model. The correlation between the variables was tested using the correlation coefficient of Spearman which does not make any assumption on the linear character of a correlation (Zuur et al., 2009). This test allow us to select only one variable among those ones being highly correlated $(|r|>0.85)$, as suggested by (Dormann et al., 2013).

The second stage was to generate, using MAXENT, a raster about the potential distribution of the species and a file containing the various statistical results of the model. This raster is obtained by introducing into the MaxEnt algorithm a csv file of the geographical co-ordinates (into decimal form) of occurence of the species and the environment variables selected. These variables are made up in bioclimatic envelopes (precipitation and temperature data for a given site). The data on the current climatic conditions were derived from the climatic data of 1950-2000, downloaded from Worldclim 1.4. For all the three models, the projections made for 2050 were used under the scenario of $\mathrm{A} 2$ emission.

Lastly, the third stage, a layer of the administrative limits and climatic zone and the raster relating to the potential distribution of the species were superimposed in Arc GIS (Young et al., 2011; Hijmans et al., 2012; Scheldeman and Van Zonneveld, 2012; Laouali et al., 2016). That allowed to chart and facilitates the localization and the measurement of the surfaces of potential distribution of $D$. mespliformis. This distribution was subdivided in four increasing scales "very favorable area (probability superior to 0.7 ), averagely favorable area (probability between 0.5 to 0.7 ), less favorable area (probability between 0.1 to 0.5 ), and unfavorable (probability inferior to 0.1 ) area to the potential distribution and the restoration of the species".

MAXENT constitutes one of the most powerful methods of modeling likely to generate very good biogeographic information while offering a good discrimination of the habitats favorable and unfavorable to a species from a bioclimatic point of view (Phillips et al., 2006). The interest of this method for this study is that it combines the data of a species occurence observed with the current bioclimatic characteristics to the points of observation to generate:

- a total map of the potential habitats of the species in the surface considered;

- a total map of the future distribution of these favorable habitats according to the climatic projections for the studied zone.

To determineTo determine the individual contribution of each selected variable, a test of Jackknife (Young et al., 2011) was carried out. This test consists of isolating the variables one by one and generates each time a model with the remaining variables and a model with the only isolated variable.

The cross validation is a process of evaluation of the effectiveness of a model which consists of dividing the data of occurence into two parts for calibration and the test of the model. The calibration of a model consists in adjusting the values of the parameters (climatic variables and points of occurence of the species) so that the simulated data correspond to the actual values (Guisan and Zimmermann, 2000; Dzotsi, 2002). For this study, $75 \%$ of the points of presence of the species were used to calibrate the model while $25 \%$ were used to test it. These same rates were used by authors such as Doko et al. (2008), Young et al. (2011), Fandohan et al. (2013), Gbesso et al. (2013), Laouali et al. (2016). To reinforce the model, it is significant to generate it on the basis of average of several repetitions of the cross validation (Young et al., 2011). For this, the cross validation was repeated 10 times for each model. The predictive capacity of the model was evaluated by using the parameter AUC (Area Under the Rock Curve) which is equivalent to probability that a point of occurence chosen randomly is located in a cell of the raster with a greater probability of occurrence of the species than a point of absence chosen randomly (Philips et al., 2006). Thus a model generated by MAXENT is described as excellent if AUC $>0.90$; good if $0.90>$ AUC $>$ 
0.80 ; acceptable if $0.80>$ AUC $>0.70$; bad if $0.70>$ AUC $>0.60$ and invalid if $0.60>A U C>0.50$ (Swets, 1988). The low value of the AUC is of 0.5 corresponding to a random prediction, and the strongest value is equal to 1 which correspond to a perfect prediction (Phillips et al., 2006).

\section{Results}

\subsection{Contribution of the Variables and Validation of the Model}

The analysis of the correlations made it possible to identify five less correlated variables $(\mathrm{R}<0.85)$ and which were used for the generation of the model. These variables are the Isothermalite (BIO3), the average temperature of the driest quarter (BIO9), the average temperature of the hottest quarter (BIO10), the annual rainfalls (BIO12) and the rainfalls of the hottest quarter (BIO3). Among these variables, the soil cover, the annual rainfalls, and the average temperature of the hottest quarter cumulate almost $90 \%$ of the contribution to the model (Table 1).

Table 1. Environment Environnement variables used and their contributions to the model

\begin{tabular}{lll}
\hline Code & Variable & Contribution (\%) \\
\hline Soil & Soil cover & 48.4 \\
BIO12 & Annual Precipitation & 21.6 \\
BIO10 & Average temperature of the warmest & 17.7 \\
Alt & Altitude & 5.8 \\
BIO18 & Precipitation of the hottest quarter & 2.6 \\
BIO3 & Isothermality & 1.9 \\
Cov & Vegetation cover & 1.3 \\
BIO9 & Average temperature of the driest quarter & 0.7 \\
\hline
\end{tabular}

The crossed validation, with an AUC of 0.95 (Figure 3) and a margin of error of $0.009(0.9 \%)$, shows a good performance of the model.

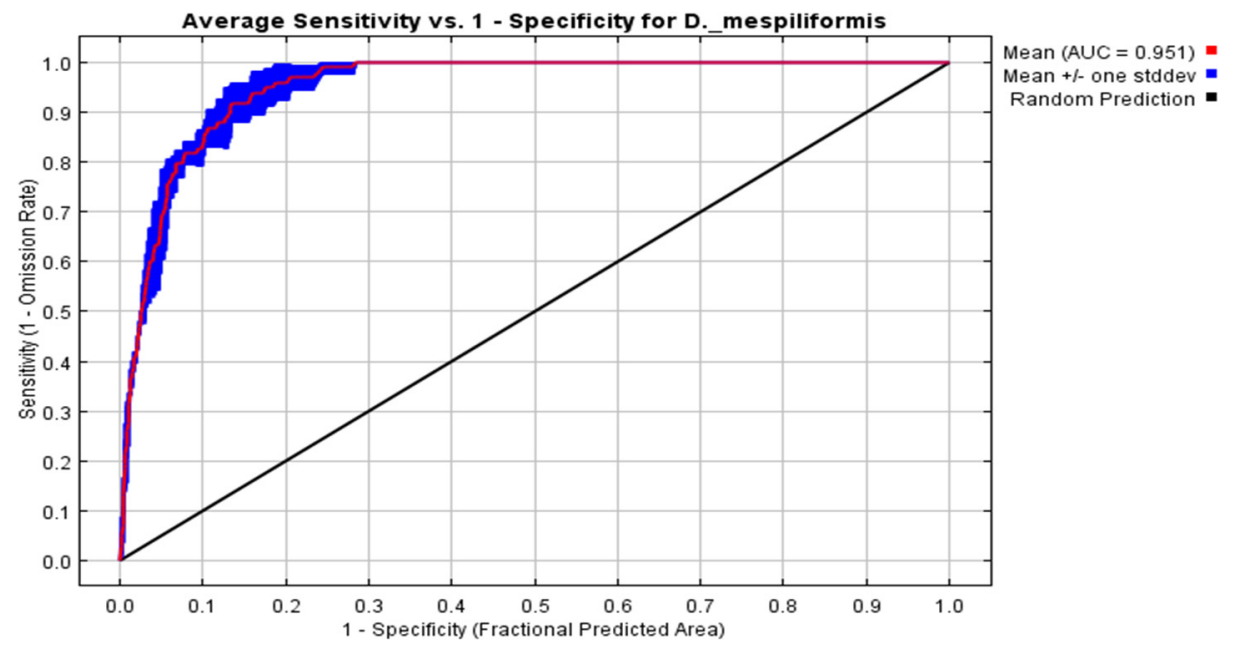

Figure 3. Curve of the sensitivity (proportion of the points of occurence) according to the predicted surface.

The test of Jackknife (Figure 4) shows the contribution of each variable used only for the realization of model. This test confirms the contribution to the model of the variables soil and Annual Precipitation with the highest profit when it is used in sulation and with the greatest loss of profit when it is omitted from the analysis while variable Average temperature of the warmest contributes less.

The "rate of omission" is a statistical variable indicator of the performance of the model. The graph "Omission and Predicted Area" presents three curves (figure 5).

-Omission one training samples (blue curve) shows the subsets of the points of presence located away from the potential surface modelled by Maxent (been worth Fraction) by the values of the threshold of probability (low and high) which delimit the predicted surface (Cumulative threshold). Training sample is synonymous with points of presence';

-Fraction of background predicted (red curve) shows the random subsets of points of the zone of study which were included in the surface predicted according to various cumulative thresholds ' Cumulative thresholds '; 
-Predicted omission (black curve) is a curve of reference.

The analysis of this figure shows how the omission of test and the formation of predicted zone vary according to the cumulative threshold. The omission on the samples of test (green line) is a very good response to the rate of omission expected (black line, by definition of the format of cumulative exit), the rate of omission for the tested data of test drawn from the distribution MaxEnt itself (orange color).

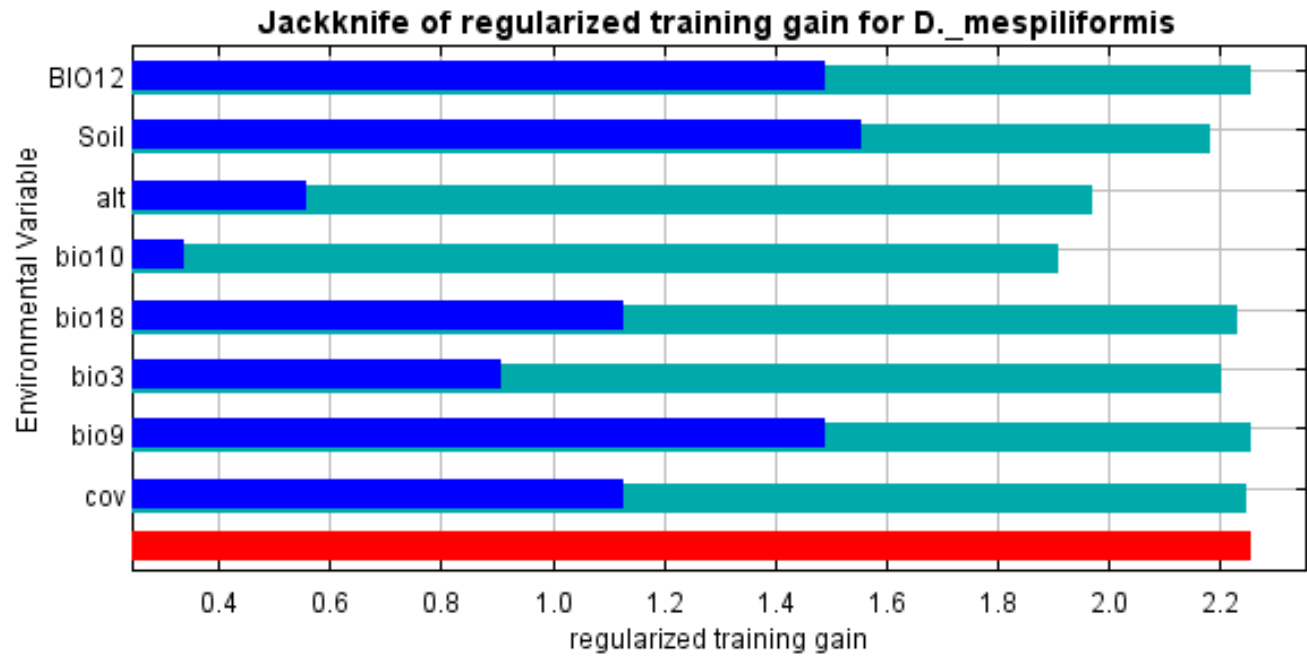

Without variable With only variable With all variables

Figure 4. Result of the test of Jackknife with the Environment variables selected

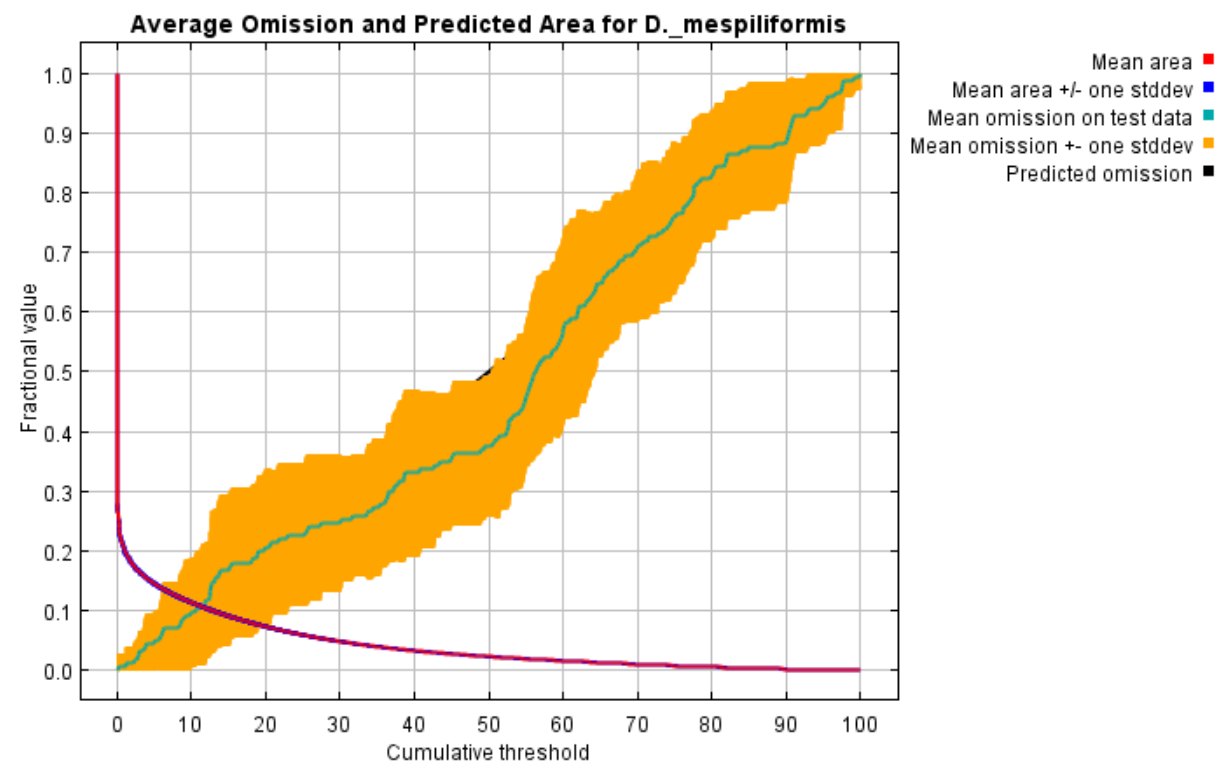

Figure 5. Graph regenerated by MAXENT showing the rate of omission and the surface predicted for $D$. mespiliformis

\subsection{Current Areas Favorable to the Potential Distribution of D. mespiliformis in Niger}

The study shows that the fundamental niche with the development of D. mespiliformis in Niger is $251198.979 \mathrm{~km}^{2}$ corresponding to $19.83 \%$ of the country. It is distributed between the sahelian, sahelo-sudanian and sudanian areas (Figure 6). The very favorable habitats cover a surface area of $36151.564 \mathrm{~km}^{2}$ corresponding to $2.85 \%$ of the country and are distributed between the sahelo-Saharan and sahelo-sudanian areas. The less favorable habitats cover a surface of $71839.370 \mathrm{~km}^{2}$ corresponding to $5.67 \%$ of the country, are located in the sahelian zone. As for 
the unfavorable habitats, with a surface area of $143208.044 \mathrm{~km}^{2}$, or $11.30 \%$ of the country, are primarily located in the sahelian and sahelo-sudanian areas.

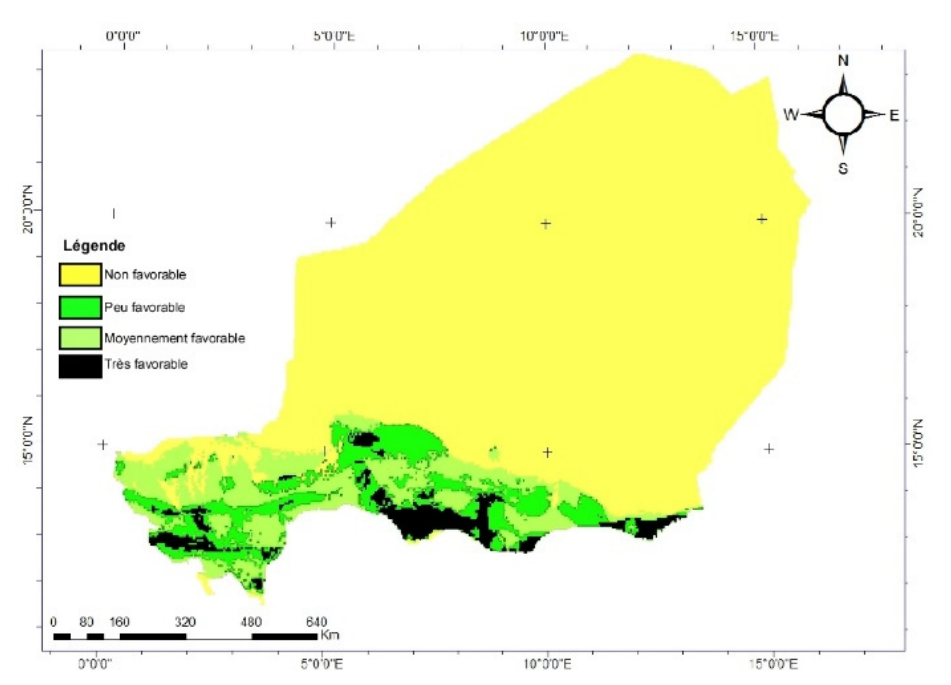

Figure 6. Area of current potential distribution of D. mespiliformis in Niger

\subsection{Impact of the climate changes on the ecological niche of D. mespiliformis}

\subsubsection{Contribution of the variables and validation of the models}

The cross validation and test of Jackknife according to the value of importance of the variables showed that the three models are excellent with AUC equal to 0.95 . The contributions of the five least correlated variables depend on the models considered. Thus, for models CCCMA and CSIRO, the BIO12 is the variable having contributed more to the models while the BIO9 has more contributed to the HadCM3 model (Table 2).

Table 2. Bioclimatic variables used and their contributions to the models according to three models

\begin{tabular}{llll}
\hline Variable & \multicolumn{1}{l}{ CCCMA } & CSIRO & HadCM3 \\
\cline { 2 - 4 } & \multicolumn{1}{l}{ Contribution en $\%$} & \\
\hline BIO3 & 8 & 8.6 & 20.7 \\
BIO9 & 10.6 & 4.4 & 40 \\
BIO10 & 5.9 & 12.6 & 5.9 \\
BIO12 & 68 & 70 & 2.5 \\
BIO18 & 2.7 & 4.4 & 30.9 \\
\hline
\end{tabular}

\subsubsection{Projection of the areas of potential distribution of $D$. mespiliformis in Niger}

Projection at the horizon of 2050 (figure 7) shows overall a light reduction in the areas of distribution of $D$. mespliformis in Niger according to models' CCCMA and SCIRO. Contrary to these models, the HadCM3 model shows an increase in the areas favorable to the development of $D$. mespliformis. 

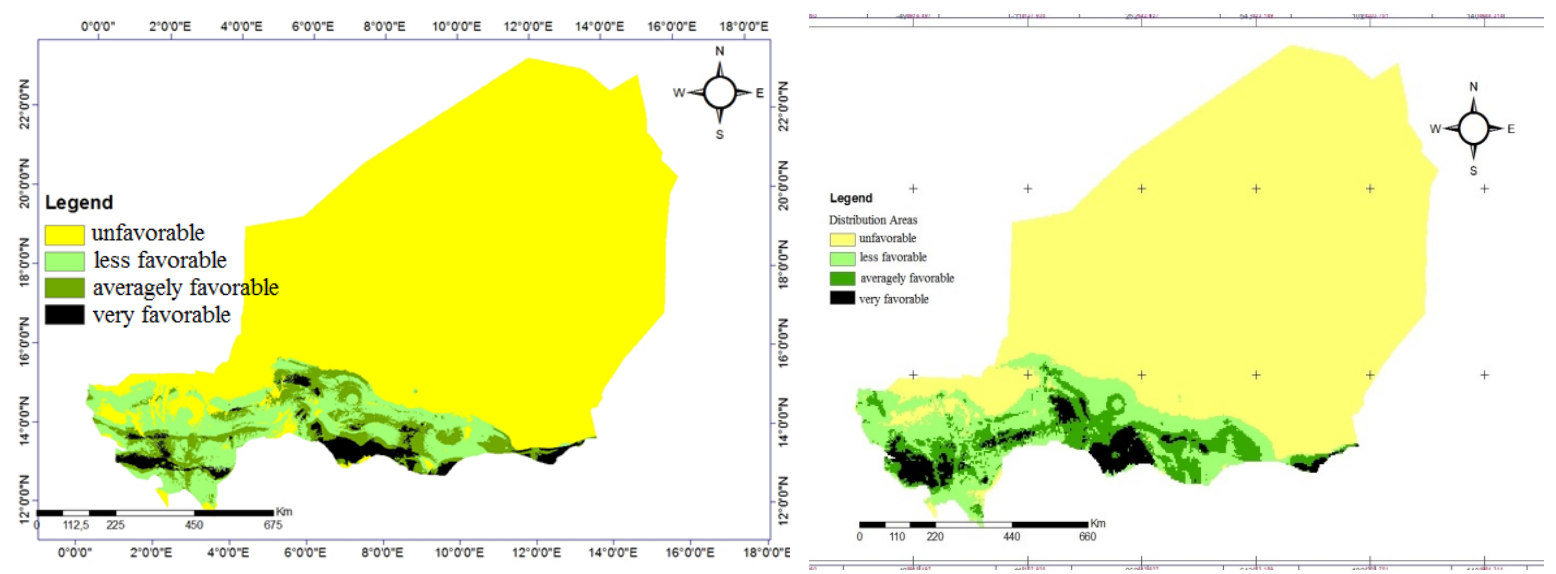

current
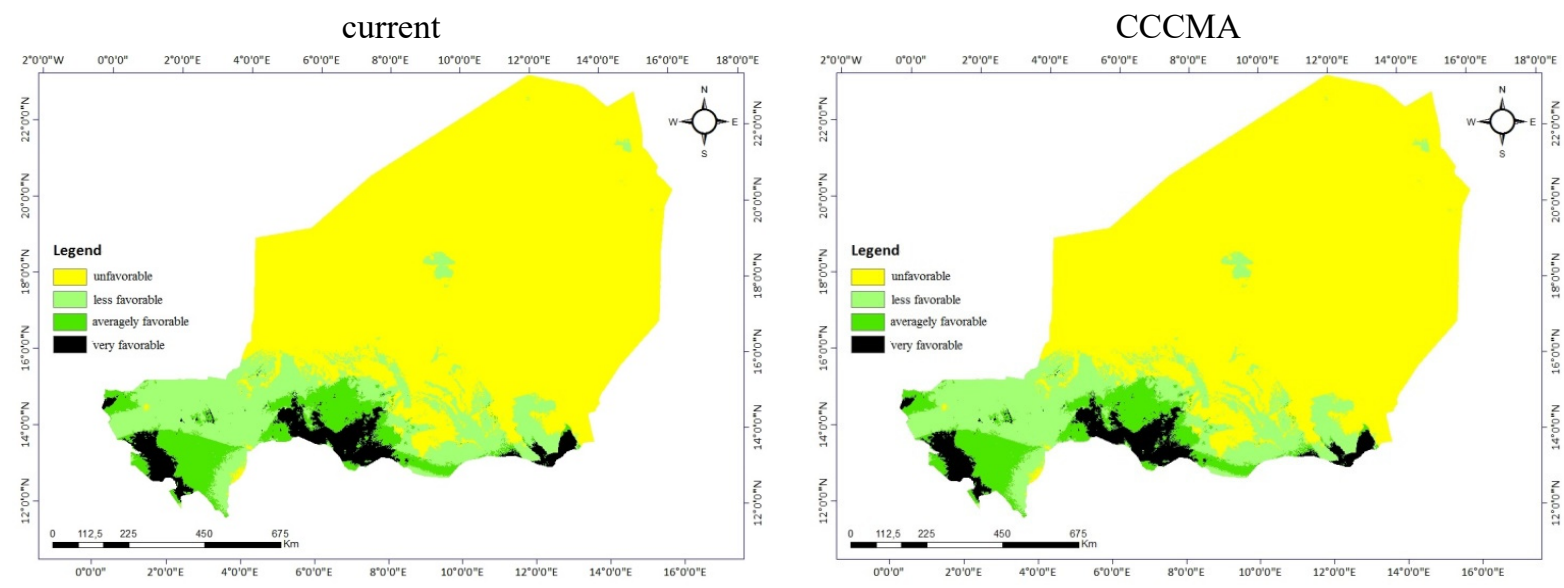

CSIRO

HadCM3

Figure 7. Distribution of the areas favorable to the development of D. mespiliformis in Niger.

According to bioclimatic projections of model CCCMA, D. mespiliformis will lose 11,35\% of its unfavorable habitat and this habitat will have set out again with the favour of the habitats fairly favorable and very favorable from here 2050 with a profit of more than $11 \%$ for the very favorable area (Table 3 ). The tendency is similar to the modelled the CSIRO. However the HadCM3 model predicated a contrary situation, projection will have a progressive tendency for the very favorable habitat with a profit of $38.15 \%$ and also for the areas fairly favorable and unfavorable. The latter will gain more than $30.64 \%$ of its current habitat.

Table 3. Dynamics of the areas favorable to the growth and or the restoration of D. mespiliformis in Niger

\begin{tabular}{|c|c|c|c|c|c|c|}
\hline \multirow{2}{*}{ Modèles } & \multicolumn{2}{|c|}{ Very favorable area } & \multicolumn{2}{|c|}{ Averagely favorable area } & \multicolumn{2}{|c|}{ Less favorable area } \\
\hline & Aire $\left(\mathbf{k m}^{2}\right)$ & Tendance (\%) & Aire $\left(\mathbf{k m}^{2}\right)$ & Tendance (\%) & Aire $\left(\mathrm{km}^{2}\right)$ & Tendance (\%) \\
\hline CURENT & 36151.56 & & 71839.37 & & 143208.04 & \\
\hline СССМА & 40175.23 & 11.13 & 75937.17 & 5.7 & 126956.38 & -11.35 \\
\hline CSIRO & 34898.01 & -3.47 & 72801.31 & 1.34 & 126603.07 & -11.59 \\
\hline HadCM3 & 49944.32 & 38.15 & 75407.49 & 4.97 & 187085.11 & 30.64 \\
\hline
\end{tabular}

\section{Discussion}

The results of this study show excellent models with a $\mathrm{AUC}=0.93$ for the current data. The habitat at present favorable to the development of $D$. mespiliformis, which accounts for $19.83 \%$ of the country, is higher than that of Prosopis africana $10.16 \%$ (Laouali et al., 2016) even if D. mespiliformis is much more dependent upon rivers than P. africana (Arbonier, 2004), especially in the West of Niger (Ali et al., 2017). The modeling of the ecological 
niches was often quoted like a powerful tool to chart the current and future distribution of species and to predict the impact of the climate changes on their distribution (Van Zonneveld et al., 2009; Nakao et al., 2010). The results of modeling show that in fact the 5 climatic variables predict the distributions of the species. That is assumed on a national scale, the distribution of $D$. mespiliformis is mainly influenced by the climatic factors. It thus reveal significant wide distribution of D. mespiliformis, an influence of the anthropic pressure on the spatial organization of the species in the landscape as isolated individuals and project by 2050 the climate effect on this species. So, these results constitute a solid base for the management of the species in Niger because others species like Prosopis julifora and Bauhinia rufessens are used in reforest program in Niger without ecological study are not give the expected results, better Prosopis julifora became invasive species in some area of Niger. However, these models also were very criticized because of their weakness in predicting the impact of the climate changes on the geographical distribution of the species. Among these weakness, we can quote uncertainties related to the models used, difficulties to parameter the ecological interactions, the individual idiosyncratic answers of the species to the climate changes, the limitations of each species disseminations, the species physiological limits and the adaptive answers of its polinisators and disseminators agents (Elith et al., 2006; Schwartz, 2012). In spite of these weaknesses, these models gave very significant bioclimatic information as regards to decision-making, in particular to identify new areas potentially favorable to the growth (Cuni-Sanchez et al., 2010) or to the conservation of a given species (Schwartz, 2012). In the same way, the cases of mortality of trees observed during the intensive droughts in the Sahel during the last century (Maranz, 2009) show the interest of climatic projections for future decision-makings. Indeed, it was recently highlighted that some trees with strong economic values were introduced into the Sahel when the climate conditions were wetter (Maranz, 2009). According to the same author, the migration of the pluviometric isohyets towards the South (sometimes below $600 \mathrm{~mm}$ for annual precipitations) would have had harmful effects on the species. The climate models can thus be used to identify the potential zones where the bioclimatic variables could significantly change values and thus influence the physiology, the productivity and the dynamics of the populations of agroforestry species. This information could then be used for the development of adequate program of production and conservation. Bioclimatic projection according to three models' constitutes a very invaluable tool in the program of the restoration of species if the need is felt by the decision makers. The models show that the omission on the samples of test is a very good response of the rate of omission envisaged, the rate of omission for the data of test drawn from the distribution MaxEnt itself. The reason is that the data of test and calibration are not independent (occurence spatially car-correlated). That indicates that the MaxEnt model was significantly better than random in the binomial test of omission and the curve of predicted area because only the data of occurence are available and not data of absence.

As a whole, the models allowed to envisage the area potentially favorable to the developments of the species. Indeed, projections show not only conditions more or less favorable for $D$. mespiliformis in Niger by 2050 but also a possible expansion of the species in areas which are currently marked as being unfavorable.

The model of the distribution of $D$. mespiliformis suggests that this species can develop in all the southern band of the country (of the sudanian area at the sahelo-sudanian area). According to developed models', especially the HadCM3 model, the climate change seems to have an effect more or less favorable to the growth, the restoration and conservation of D. mespiliformis in Niger which shows a total increase of $24 \%$ on the southern part of the country but some areas in the currently arid lands. That makes it possible to confirm partially the assumption of the departure "the climate strongly influences the dynamics of the species in Niger". This situation is due to the fact that the variables which contributed more to the model parameterization are the average temperature of the driest quarter and the cumulated level of precipitations during the hottest quarter which will be in increase in the Sahel following the future projection of the climate.

These results showed that the trend of area distribution are same with the results obtained by Fandohan et al. (2013) on Tamarindus indica and Gouwakinnou et al. (2011) on Sclerocarya birrea which are species of the sudanian areas, Containing sodé et al. (2013) on Dialium guineense and Gbesso et al. (2013) on Chrysophyllum albidum, some edible fruit-bearing species of the same ecological area as D. mespliformis. However the downward trend observed for area distribution of some species in humid zone (Piedallu et al .,2013) In a changing environment, to predict the variations of the distribution of the species can be a significant stake, in particular in terms of management and domestication of the species. In addition, the recent evolution of the statistical techniques and the geographical information systems allows to consider models of distribution much more satisfactory (Elith and Leathwick, 2009).

\section{Conclusion}

The climate change is a factor that contributes to the degradation or even the extinction of much of species especially in the Sahel. The determination of ecological niche and the impact of the current and future climate 
variability show a good adaptation of $D$. mespiliformis. This study showed new possibilities on $D$. mespiliformis management in Niger because the forecasting the most favorable geographic areas changes under expected climate conditions in 2050 indicate an augmentation their area. Taking into account the socio-economic importance of this species and its resilience to the climate changes, operations of restoration through an implementation of afforestation program for species must be considered in all the habitats favorable to its development.

\section{References}

Arbonnier, M. (2000). Arbres, arbustes et lianes des zones sèches d'Afrique de l'Ouest. CIRAD - MNHN - UICN, Montpellier (France). 541p.

Austin, M. (2007). Species distribution models and ecological theory: A critical assessment and some possible new approaches. Ecological Modelling, 200(1-2), 1-19. doi:10.1016/j.ecolmodel.2006.07.005

Doko, T., Kooiman, F. A., \& Toxopeus, A. G. (2008). Modeling of species geographic distribution for assessing present needs for the ecological networks. The International Archives of the Photogrammetry, Remote Sensing and Spatial Information Sciences, XXXVII (Part B4. Beijing), 267-276.

Dormann, C. F., Elith, J., Bacher, S., Buchmann, C., Carl, G., Carré, G., ... Lautenbach, S. (2013). Collinearity: A review of methods to deal with it and a simulation study evaluating their performance. Ecography, 36(1), 27-46. doi:10.1111/j.1600-0587.2012.07348.x

Doztsi, A. K. (2002). Application du modèle CERES-Maize de DSSAT à l'analyse des stratégies de semis pour le maïs (Zea mays L.) dans les conditions de SEVE KPOTA. Mémoire d'ingénieur agronome, IFDC Afrique/ESA -UL, Lomé, Togo.64p.

Elith, J., H. Graham, C., P. Anderson, R., Dudík, M., Ferrier, S., Guisan, A., ... E. Zimmermann, N. (2006). Novel methods improve prediction of species' distributions from occurrence data. Ecography, 29(2), 129-151. doi:10.1111/j.2006.0906-7590.04596.x

Fandohan, B., Gouwakinnou, G. N., Fonton, N. H., Sinsin, B., \& Liu, J. (2013). Impact des changements climatiques sur la répartition géographique des aires favorables à la culture et à la conservation des fruitiers sous-utilisés : cas du tamarinier au Bénin. Biotechnology Agronomy and Society Environment, 17(3), 450462.

Gbesso, F., Tente, B., Gouwakinnou, G., \& Sinsin, B. (2014). Influence des changements climatiques sur la distribution géographique de Chrysophyllum albidum G. Don (Sapotaceae) au Benin. International Journal of Biological and Chemical Sciences, 7(5), 2007-2018. doi:10.4314/ijbcs.v7i5.18

Gouwakinnou, N. G. (2011). Population ecology, uses and conservation of Sclerocarya birrea (A. Rich) Hocchst. (Anacardiaceae) in Benin, West Africa (Doctoral Dissertation). University of Abomey Calavi, Republic of Benin.

Guisan, A., \& Thuiller, W. (2005). Predicting species distribution: Offering more than simple habitat models. Ecology Letters, 8(9), 993-1009. doi:10.1111/j.1461-0248.2005.00792.x

Guisan, A., \& Zimmermann, N. E. (2000). Predictive habitat distribution models in ecology. Ecological Modelling, 135(2-3), 147-186. doi:10.1016/S0304-3800(00)00354-9

Hijmans, R. J., Cameron, S. E., Parra, J. L., Jones, P. G., \& Jarvis, A. (2005). Very high resolution interpolated climate surfaces for global land areas. International Journal of Climatology, 25(15), 1965-1978. doi:10.1002/joc. 1276

Hijmans, R. J., Luigi, G., \& Prem, M. (2012). DIVAGIS Version 7.5 Manual. Retrieved from http://www.diva gis.org/docs/DIVA-GIS_manual_7.pdf

Kumar, S., \& Stohlgren, T. J. (2009). Maxent modeling for predicting suitable habitat for threatened and endangered tree Canacomyrica monticola in New Caledonia. Journal of Ecology and Natural Environment, 1(4), 094-098.

Mahamane, A., Morou, B., Zaman-Allah, M., Saadou, M., Saley, K., Bakasso, Y., \& Jauffret, S. (2012). Climate Variability in Niger: Potential Impacts on vegetation distribution and productivity. Journal of Environmental Science and Engineering, B1, 49-57.

Maranz, S. (2009). Tree mortality in the African Sahel indicates an anthropogenic ecosystem displaced by climate change. Journal of Biogeography, 36(6), 1181-1193. doi:10.1111/j.1365-2699.2008.02081.x 
Nakao, K., Matsui, T., Horikawa, M., Tsuyama, I., \& Tanaka, N. (2011). Assessing the impact of land use and climate change on the evergreen broad-leaved species of Quercus acuta in Japan. Plant Ecology, 212(2), 229 243. doi:10.1007/s11258-010-9817-7

Ouoba, P. A., Dapola, E. C. Da, \& Paré, S. (2014). Perception locale de la dynamique du peuplement ligneux des vingt dernières années au Sahel burkinabé. VertigO, (Volume 14 Numéro 2). doi:10.4000/vertigo.15131

Ozer, P., \& Erpicum, M. (1995). Méthodologie pour une meilleure représentation spatio-temporelle des fluctuations pluviométriques observées au Niger depuis 1905. Sécheresse, 1(6), 103-108.

Phillips, S. J., Anderson, R. P., \& Schapire, R. E. (2006). Maximum entropy modeling of species geographic distributions. Ecological Modelling, 190(3-4), 231-259. doi:10.1016/j.ecolmodel.2005.03.026

Saadou, M. (1990). La végétation des milieux drainés nigériens à l'Est du fleuve Niger. Thèse de Doctorat ès Sciences Naturelles. Université de Niamey.

Sampoux. J.P, Badeau. V; (2009). Modélisation de la niche écologique des fétuques à feuilles fines: quels apports pour la conservation et la valorisation des ressources génétiques ?.Innovations Agronomiques, 7, 79-91.

Scheldeman, X., \& Van Zonneveld, M. (2010). Training manual on spatial analysis of plant diversity and distribution. Bioversity International, Rome, Italy.

Schmidt, M., König, K., \& Müller, J. V. (2008). Modelling species richness and life form composition in Sahelian Burkina Faso with remote sensing data. Journal of Arid Environments, 72(8), 1506-1517. doi:10.1016/j.jaridenv.2008.02.015

Sop, T. K., Oldeland, J., Schmiedel, U., Ouedraogo, I., \& Thiombiano, A. (2011). Population structure of three woody species in four ethnic domains of the sub-sahel of Burkina Faso. Land Degradation and Development, 22(6), 519-529. doi:10.1002/ldr.1026

Williams, J. W., Jackson, S. T., \& Kutzbach, J. E. (2007). Projected distributions of novel and disappearing climates by 2100 AD. Proceedings of the National Academy of Sciences of the United States of America, 104(14), 5738-5742. doi:10.1073/pnas.0606292104

Wittig, R., Schmidt, M., \& et Thiombiano, A. (2004). Cartes de distribution des espèces du genre Acacia L. au Burkina Faso. Etudes Flore vegetation. Burkina Faso, 8, 19-26.

Young, N., Carter, L., \& Evangelista, P. (2011). A MaxEnt Model v3.3.3e Tutorial (ArcGIS v10). Laboratory at Colorado State University and the National Institute of Invasive Species Science. Retrieved from http://ibis.colostate.edu/WebContent/WS/ColoradoView/TutorialsDownloads/A_Maxent_Model_v7.pdf

Zuur, A. F., Ieno, E. N., Walker, N. J., Saveliev, A. A., \& Smith, G. M. (2009). Mixed Effetcts Models and Extensions in Ecology with R. Berlin: Springer.

\section{Copyrights}

Copyright for this article is retained by the author(s), with first publication rights granted to the journal.

This is an open-access article distributed under the terms and conditions of the Creative Commons Attribution license (http://creativecommons.org/licenses/by/4.0/). 